\title{
A RETROSPECTIVE STUDY ON ADHERENT PLACENTA- ITS MANAGEMENT, MATERNAL AND PERINATAL OUTCOME
}

\author{
Atal Bihari Dandapat¹, Benudhar Pande2, Santosh Kumar Dora3 ${ }^{3}$ Kishore Chandra Mohapatra4, Lal Mohan Nayak ${ }^{5}$ \\ ${ }^{1}$ Assistant Professor, Department of Obstetrics and Gynaecology, VIMSAR, Burla, Odisha, India. \\ ${ }^{2}$ Assistant Professor, Department of Obstetrics and Gynaecology, VIMSAR, Burla, Odisha, India. \\ ${ }^{3}$ Assistant Professor, Department of Obstetrics and Gynaecology, VIMSAR, Burla, Odisha, India. \\ ${ }^{4}$ Senior Resident, Department of Obstetrics and Gynaecology, VIMSAR, Burla, Odisha, India. \\ ${ }_{5}^{5}$ Associate Professor, Department of Obstetrics and Gynaecology, VIMSAR, Burla, Odisha, India.
}

\section{ABSTRACT}

\section{BACKGROUND}

Morbidly adherent placenta is on rise due to the increasing incidence of caesarean section and other uterine surgery. The aim of the study was to identify the risk factors predisposing to morbidly adherent placenta and its management, maternal and perinatal outcome of these patients.

\section{MATERIALS AND METHODS}

This was a retrospective observational study conducted in the Department of Obstetrics and Gynaecology, VIMSAR, Burla, India from March 2015 to February 2017.

\section{RESULTS}

In the present study, there was a total of 21 patients diagnosed of morbidly adherent placenta with the incidence of 1.14 per 1000 pregnancies. Previous caesarean along with placenta previa constitutes 13 (61.90\%), which is the main risk factor for the development of morbidly adherent placenta. Out of 21 patients $17(80.95 \%)$ require hysterectomy, 2 (9.52\%) managed with subtotal hysterectomy and $2(9.52 \%)$ managed conservatively. Five $(23.80 \%)$ patients had bladder injury. The mean blood loss during surgery was $2.1 \pm 0.312$ litre. One case of placenta percreta who later on developed disseminated intravascular coagulation died of the disease. Seventeen (80.95\%) of the patients had live birth and 4 (19.05\%) had fresh still birth. Six (28.57\%) babies admitted in a neonatal ICU for better care. Out of 21 babies, 6 (28.57\%) required neonatal intensive care for neonatal complications.

\section{CONCLUSION}

Patients with previous caesarean with placenta previa always should be referred to the nearest tertiary care centre keeping adherent placenta as a possibility. It is always preferable to take the help of a senior obstetrician in such cases to reduce the morbidity and mortality.

\section{KEYWORDS}

Placenta Accreta, Increta and Percreta; Previous Caesarean Section; Peripartum Hysterectomy; Internal Iliac Artery Ligation.

HOW TO CITE THIS ARTICLE: Dandapat AB, Pande B, Dora SK, et al. A retrospective study on adherent placenta- its management, maternal and perinatal outcome. J. Evolution Med. Dent. Sci. 2017;6(34):2785-2788, DOI: 10.14260/Jemds/2017/600
BACKGROUND
Morbidly Adherent Placenta (MAP) includes placenta accreta, placenta increta and placenta percreta. Detachment is delayed in MAP, because the placenta is unusually adhered to the implantation site. In this case, the decidua is scanty or absent, and the physiological line of cleavage through the decidual spongy layer is lacking. Incidence of MAP is on rise due to increasing trend in caesarean section rate. ${ }^{1,2}$ The incidence of MAP in $\mathrm{USA}^{3,4}$ is 1 in 2500, that of in Canada ${ }^{5}$ is 14.4 per 10,000 and in $\mathrm{UK}^{6}$ it is 1.7 per 10,000 . Besides caesarean section surgery involving uterus like myomectomy,
Obstetric haemorrhage is one of the leading cause of maternal death in developing nation, especially in India. In developing country, majority of these placental abnormalities were diagnosed after delivery. These women are at more risk of developing Post-Partum Haemorrhage (PPH), peripartum hysterectomy, bladder injury and multiple blood transfusions. They should be preferably delivered in a tertiary care hospital.8,9 We conducted a retrospective study at our institution to identify the demographic profile of patients with MAP, materno-foetal outcome, its complications and its management. dilatation and curettage, previous hysterotomy all lead to abnormality in placental implantation and defective Nitabuch layer formation. All this also predisposes the women to have placenta previa and more ominously MAP. ${ }^{7}$

Financial or Other, Competing Interest: None.

Submission 06-04-2017, Peer Review 19-04-2017,

Acceptance 21-04-2017, Published 27-04-2017.

Corresponding Author:

Atal Bihari Dandapat,

Department of Obstetrics and Gynaecology,

VIMSAR, Burla, Odisha, India.

E-mail: dratalog@gmail.com

DOI: $10.14260 /$ jemds $/ 2017 / 600$

\section{MATERIALS AND METHODS \\ Type of Study}

Hospital based retrospective observational study. Medical records of all cases, MAP were retrieved and analysed.

\section{Place of Study}

This study was conducted in the Department of Obstetrics and Gynaecology, VIMSAR, Burla, India.

\section{Duration of Study}

From $1^{\text {st }}$ March 2015 to $28^{\text {th }}$ February 2017. 


\section{Study Population}

All women with confirmed diagnosis of adherent placenta admitted and managed in the above mentioned hospital. Demographic data like age, parity, period of gestation, any uterine surgery including caesarean section, history of dilatation and curettage, past obstetrics and medical history, intraoperative details, blood loss, procedure to control blood loss, intraoperative complications if any noted. Neonatal outcome like birth weight, perinatal mortality and nursery stay noted. Records reviewed regarding the mode of diagnosis of MAP. MAP diagnosed in USG colour Doppler, Magnetic Resonance Imaging (MRI) or had been diagnosed intraoperative period with adherent placenta noted.

\section{RESULTS}

There were 18433 deliveries during the study period, of which 21 patients had morbidly adherent placenta giving an incidence of 1.14 per 1000 pregnancies. The maximum number of women belonged to the age group of 25 - 30 constituting $11(52.38 \%)$ with a mean age of $29.19 \pm 3.98$ years. The mean number of gravida in the study group was $2.61 \pm 0.97$ with $13(61.90 \%)$ were of gravida 3 or more. Only $5(23.8 \%)$ patients were booked with our institution with rest of the patients either booked with some other institution or referred. All the demographic details is in Table 1.

In the present study, 13 (61.90\%) had previous caesarean section. Association of placenta previa with caesarean section was diagnosed in 13 (61.90\%) of patients. When we have analysed previous caesarean patients, we have seen 5 (38.46\%) patients had previous 2 and 3 caesarean sections each. Previous 1 caesarean is seen in $3(23.08 \%)$ of the patients. Myomectomy was the risk factor for MAP in 5 $(23.80 \%)$ of patients. One patient had previous history of dilatation and curettage for unwanted pregnancy in 2 (9\%) patients did not have any identifiable risk factor for MAP. Placenta accrete was found in 11 (52.38\%), placenta increta in $8(38.09 \%)$ and placenta percreta in $2(9.52 \%)$ of the patients. In all patients, diagnosis of MAP was confirmed during intraoperative period. Two patients (9.57\%) were diagnosed with morbidly adherent placenta in the postpartum period and both of them were referred from a nearby hospital. Massive blood loss during surgery was a commonest feature seen in all the patients. A mean blood loss of $2.1 \pm$ 0.312 litre was seen with an average 6 unit blood transfusion was done. Fifteen patients constituting $71.42 \%$ patient had severe anaemia of less than 7 grams haemoglobin.

Out of $21(90.47 \%), 19$ patients required hysterectomy due to MAP and 2 (9.5\%) managed conservatively with methotrexate. Caesarean hysterectomy with internal iliac artery ligation was done in 5 (23\%), caesarean hysterectomy with bladder repair in 5 (23\%), 7 (33.33\%) managed with only hysterectomy following caesarean and 2 (9.5\%) patients managed with subtotal hysterectomy. Details of management of MPA is in Table 2. One patient died of Disseminated Intravascular Coagulation (DIC) who presented with placenta percreta. Apart from maternal mortality, they are also more prone to have maternal complications. In our series bladder injury requiring repair is seen in $5(23.80 \%)$, surgical site infection in 6 (28.57\%), DIC 4 (19.04\%) and 11 (52.38\%) patients required ICU care after surgery. Details of maternal complications are in Table 3. Seventeen (80.95\%) of the patients had live birth and $4(19.05 \%)$ had fresh still birth.
Ten (47.61\%) of babies were born preterm ( $<37$ weeks) with a mean birth weight of $2224 \pm 372$ grams. Six $(28.57 \%)$ of babies born required Neonatal Intensive Care Unit (NICU) admission for low birth weight, respiratory distress and neonatal jaundice. Foetal outcome is tabulated in Table 4 .

\begin{tabular}{|c|c|c|c|c|}
\hline $\begin{array}{l}\text { Sl. } \\
\text { No. }\end{array}$ & \multicolumn{2}{|c|}{$\begin{array}{c}\text { Demographic } \\
\text { Variable }\end{array}$} & $\begin{array}{c}\text { No. of } \\
\text { Patients }\end{array}$ & $\%$ \\
\hline \multirow{4}{*}{1} & \multirow{4}{*}{ Age } & $20-25$ years & 2 & 9.52 \\
\hline & & 25 - 30 years & 11 & 52.38 \\
\hline & & 30 - 35 years & 6 & 28.57 \\
\hline & & $>35$ years & 2 & 9.52 \\
\hline \multirow{3}{*}{2} & \multirow{3}{*}{$\begin{array}{l}\text { Registration } \\
\text { Status }\end{array}$} & Booked & 5 & 23.80 \\
\hline & & Referred & 14 & 66.66 \\
\hline & & Unbooked & 2 & 9.52 \\
\hline \multirow{4}{*}{3} & \multirow{4}{*}{ Gravidity } & Gravida-1 & 3 & 14.28 \\
\hline & & Gravida-2 & 5 & 23.80 \\
\hline & & Gravida-3 & 11 & 52.38 \\
\hline & & Gravida- 4 or more & 2 & 9.52 \\
\hline \multirow{6}{*}{4} & \multirow{6}{*}{$\begin{array}{l}\text { Associated } \\
\text { Risk } \\
\text { Factors }\end{array}$} & Previous Caesarean & & \\
\hline & & Previous Curettage & 13 & 61.90 \\
\hline & & No identifiable risk & 1 & 4.76 \\
\hline & & factor & 2 & 9.52 \\
\hline & & Myomectomy & 5 & 23.80 \\
\hline & & $\begin{array}{l}\text { Placenta Previa with } \\
\text { previous caesarean }\end{array}$ & 13 & 61.90 \\
\hline \multirow{3}{*}{5} & Previous & 1 Caesarean & 3 & 23.07 \\
\hline & Caesarean & 2 Caesarean & 5 & 38.46 \\
\hline & & 3 Caesarean & 5 & 38.46 \\
\hline \multirow{3}{*}{6} & \multirow{3}{*}{$\begin{array}{c}\text { Type of } \\
\text { Placentation }\end{array}$} & Accreta & 11 & 52.38 \\
\hline & & Increta & 8 & 38.09 \\
\hline & & Percreta & 2 & 9.52 \\
\hline \multirow{2}{*}{7} & Diagnosis of & Antepartum & 19 & 90.47 \\
\hline & MAP & Post-partum & 02 & 9.52 \\
\hline \multirow{4}{*}{8} & \multirow{4}{*}{$\begin{array}{c}\text { Gestational } \\
\text { Age of } \\
\text { Delivery }\end{array}$} & 24 - 28 Weeks & 1 & 4.7 \\
\hline & & 29 - 33 Weeks & 3 & 14.2 \\
\hline & & 34 - 38 Weeks & 15 & 71 \\
\hline & & $>38$ Weeks & 2 & 9.52 \\
\hline \multirow[b]{2}{*}{9} & \multirow[b]{2}{*}{ Anaemia } & Moderate & 06 & 28.57 \\
\hline & & $\begin{array}{c}(7-9.9 \mathrm{gm} \%) \\
\text { Severe }(<7 \mathrm{gm} \%)\end{array}$ & 15 & 71.42 \\
\hline & le 1. & cidence, Demogral & Profil & Risk \\
\hline
\end{tabular}

MAP- Morbidly Adherent Placenta.

\begin{tabular}{|c|c|c|c|}
\hline $\begin{array}{c}\text { Sl. } \\
\text { No. }\end{array}$ & $\begin{array}{c}\text { Treatment } \\
\text { Modality }\end{array}$ & $\begin{array}{c}\text { No. of } \\
\text { Patient }\end{array}$ & $\begin{array}{c}\text { Percentage } \\
\text { (\%) }\end{array}$ \\
\hline 1 & $\begin{array}{c}\text { Hysterectomy with } \\
\text { Internal Iliac Artery } \\
\text { Ligation }\end{array}$ & 5 & 23.8 \\
\hline 2 & Hysterectomy & 7 & 33.33 \\
\hline 3 & Subtotal Hysterectomy & 2 & 9.5 \\
\hline 4 & $\begin{array}{c}\text { Hysterectomy with } \\
\text { Bladder Repair }\end{array}$ & 5 & 23.8 \\
\hline 5 & $\begin{array}{c}\text { Medical Management } \\
\text { (Methotrexate) without } \\
\text { Hysterectomy }\end{array}$ & 2 & 9.5 \\
\hline \multicolumn{3}{|c|}{ Table 2. (Treatment Modality) } \\
\hline
\end{tabular}




\begin{tabular}{|c|c|}
\hline Complications & Number (Percentage) \\
\hline Bladder injury & $5(23.8 \%)$ \\
\hline Surgical site infection & $6(28.57 \%)$ \\
\hline $\begin{array}{l}\text { Disseminated intravascular } \\
\text { coagulation }\end{array}$ & $4(19.04 \%)$ \\
\hline ICU transfer & $11(52.38 \%)$ \\
\hline Maternal death & $1(4.76 \%)$ \\
\hline
\end{tabular}

\begin{tabular}{|c|c|}
\hline Foetal Parameter & N (Percentage) \\
\hline Live born & $17(80.95 \%)$ \\
Still born & $04(19.05 \%)$ \\
\hline Preterm delivery $(<37$ weeks) & $10(47.61 \%)$ \\
\hline Birth weight & $2224 \pm 372$ grams \\
\hline NICU admission & $6(28.57 \%)$ \\
\hline \multicolumn{2}{|c|}{ Table 4. (Neonatal Outcome) }
\end{tabular}

\section{DISCUSSION}

Adherent placenta is characterised by abnormal attachment of placental villi directly to myometrium due to scanty or absence of decidua basalis and imperfect development of fibrinoid on Nitabuch layer. Placental villi are attached to myometrium in placenta accreta. In placenta increta villi actually invade into the myometrium, but in case of placenta percreta villi penetrate through the myometrium up to the serosal layer. ${ }^{10}$ The urinary bladder is the most frequently involved extrauterine organ, when there is a placenta percreta. ${ }^{11}$ In the present study, 5 patients had urinary bladder injury constituting about 23\% requiring repair during hysterectomy. When there is an extension of the placenta to the parametrium, there may be significant risk to the ureteric injury; in those cases, preoperative ureteric stenting may be helpful to identify the ureter. In this study, it is evident that morbidly adherent placenta usually occurs in subsequent pregnancies explaining the older age group and higher gravidity of the patients.

The most important risk factors for MPA are previous caesarean delivery, placenta previa, multiparity and advanced maternal age. As the number of caesarean section increases, there is increase in the incidence of placenta previa. A recent meta-analysis study published in between 1990 to 2011 revealed that after a caesarean delivery the calculated odd ratio for placenta previa is 1.47 .12 The chances of having MPA is increased many folds if placenta previa is associated with previous caesarean section. In the present study, $100 \%$ of the patients who had previous caesarean also had placenta previa. The incidence of MPA with 1 caesarean is $0.3 \%$, whereas previous caesarean with placenta previa incidence is $11 \%$. Similarly, for previous 3 caesareans without placenta previa incidence is $2.3 \%$ and with placenta previa it is $61 \% .^{13}$ Antenatally, they can be diagnosed as MPA with the help of USG colour Doppler and magnetic resonance imaging study. A recent meta-analysis including 3641 patients with MPA revealed the sensitivity of USG for the diagnosis of MPA is over $90 \% .^{14}$ The sensitivity of MRI ${ }^{15}$ for the diagnosis of MPA is over $94 \%$, so this is a better modality for the diagnosis and it is to be preferred over USG where facility is available. As $16(76.19 \%)$ patients were unbooked and referred from a peripheral hospital, most of them were diagnosed to have MPA in the operation table leading to high morbidity. The optimal time for delivery is believed to be between 34 - 35 weeks in most cases. ${ }^{16}$ In our series, 15
(71.42\%) delivered between 34 to 38 weeks. Two patients had vaginal delivery at 38 weeks and they referred with retained placenta. In both patients USG was done, which suggests MPA for which laparotomy with subsequent hysterectomy was done. The recommended management of suspected adherent placenta is planned preterm caesarean section with placenta left in situ, because attempts at removal of placenta are associated with significant haemorrhagic morbidity. ${ }^{17}$ In 7 (33.33\%) patients we had removed placenta piecemeal, as in all those patients we do not have preoperative diagnosis of MPA and they all were diagnosed surgery. Due to this, there was an increase in blood loss during surgery. In the present study, the mean blood loss was $2.1 \pm 0.312$ litre. In carefully selected patients, methotrexate can be tried for conservative management. We have managed two cases with methotrexate therapy. The recent studies no longer advocate the use of methotrexate therapy for conservative management of MPA, as it is not so helpful.18,19

Maternal mortality for MAP is reported to be between 7 $10 \%$ worldwide. Maternal morbidity had been reported to occur in up to $60 \%$ of women. There is a substantial risk of mortality and morbidity like severe haemorrhage, coagulopathy, infection, sepsis, uterine perforation, need for blood transfusion, bladder injury and hysterectomy in MAP. Uterus preserving treatment may have a role in carefully selected patients who desire future fertility; several adjuvant techniques have been proposed along with surgery. These include internal iliac artery ligation uterine, artery embolisation, balloon tipped catheter to internal iliac artery ${ }^{20}$ treatment. We managed two cases of MPA conservatively without any major complications.

\section{CONCLUSION}

Efforts are ongoing to better identify MAP during antepartum period. Antenatal diagnosis of MAP through imaging (USG colour Doppler/MRI) should be carried out in high risk patients. This study emphasises the importance of proper antenatal checkup as well as timely referral of MAP women. But in many developing countries including India, getting an USG or MRI facility is a distant dream in many places. Patients with previous caesarean with placenta previa always should be referred to the nearest tertiary care centre at the earliest. Patients with the above risk factor even if we do not have any preoperative USG or MRI, MAP always to be kept as a possibility. It is always preferable to take the help of a senior obstetrician in such cases. Multidisciplinary planning and treatment in a tertiary care centre can minimise maternal and perinatal morbidity and mortality. Interventional radiological procedures may help in preserving the uterus and hence the future fertility career of the patients.

\section{ACKNOWLEDGEMENT}

The author is grateful to all resident faculties and staff members in the Department of Obstetrics and Gynaecology, VSS Medical College Hospital, Burla for their help, support and assistance.

\section{REFERENCES}

[1] Chattopadhyay SK, Kharif H, Sherbeeni MM. Placenta praevia and accreta after previous caesarean section. Eur J Obstet Gynecol Reprod Biol 1993;52(3):151-6. 
[2] To WW, Leung WC. Placenta previa and previous cesarean section. Int J Gynaecol Obstet 1995;51(1):2531.

[3] Timor-Tritsch IE, Monteagudo A. Unforeseen consequences of the increasing rate of cesarean deliveries: early placenta accreta and cesarean scar pregnancy. A review. Am J Obstet Gynecol 2012;207(1):14-29.

[4] ACOG Committee on Obstetric Practice. ACOG Committee opinion \#266, January 2002: placenta accreta. Obstet Gynecol 2002;99(1):169-70.

[5] Mehrabadi A, Hutcheon JA, Liu S, et al. Contribution of placenta accreta to the incidence of postpartum hemorrhage and severe postpartum hemorrhage. Obstet Gynecol 2015;125(4):814-21.

[6] Fitzpatrick KE, Sellers S, Spark P, et al. Incidence and risk factors for placenta accreta/increta/percreta in the UK: a national case-control study. PLoS One 2012;7(12):e52893.

[7] Wu S, Kocherginsky M, Hibbard JU. Abnormal placentation: twenty-year analysis. Am J Obstet Gynecol 2005;192(5):1458-61.

[8] Publications Committee, Society for Maternal-Fetal Medicine, Belfort MA. Placenta accreta. American Journal of Obstetrics and Gynecology 2010;203(5): 430-9.

[9] Committee on Obstetric Practice. ACOG. Committee opinion no. 529: placenta accreta. Obstet Gynecol 2012;120(1):207-11.

[10] Benirschke K, Burton GJ, Baergen RN. Pathology of the Human Placenta. Pathology of Trophoblast Invasion. $6^{\text {th }}$ edn. New York: Springer 2013:205-11.

[11] Perez-Delboy A, Wright JD. Surgical management of placenta accreta: to leave or remove the placenta? BJOG 2014;121(2):163-70.
[12] Klar M, Michels KB. Cesarean section and placental disorders in subsequent pregnancies--a meta-analysis. J Perinat Med 2014;42(5):571-83.

[13] Wong HS, Hutton J, Zuccollo J, et al. The maternal outcome in placenta accreta: the significance of antenatal diagnosis and non-separation of placenta at delivery. N Z Med J 2008;121(1277):30-8.

[14] D'Antonio F, Iacovella C, Bhide A. Prenatal identification of invasive placentation using ultrasound: systematic review and meta-analysis. Ultrasound Obstet Gynecol 2013;42(5):509-17.

[15] D'Antonio F, Iacovella C, Palacios-Jaraquemada J, et al. Prenatal identification of invasive placentation using Magnetic Resonance Imaging (MRI): systematic review and meta-analysis. Ultrasound Obstet Gynecol 2014;44(1):8-16.

[16] Robinson BK, Grobman WA. Effectiveness of timing strategies for delivery of individuals with placenta previa and accreta. Obstet Gynecol 2010;116(4): 835-42.

[17] Fitzpatrick KE, Sellers S, Spark P, et al. The management and outcomes of placenta accreta, increta and percreta in the UK: a population-based descriptive study. BJOG 2014;121(1):62-71.

[18] Sentilhes L, Goffinet F, Kayem G. Management of placenta accreta. Acta Obstet Gynecol Scand 2013;92(10):1125-34.

[19] Bisschop SCN, Schaap TP, Vogelvang TE, et al. Invasive placentation and uterus preserving treatment modalities: a systematic review. Arch Gynecol Obstet 2011;284(2):491-502.

[20] Clausen C, Stensballe J, Albrechtsen CK, et al. Balloon occlusion of the internal iliac arteries in the multidisciplinary management of placenta percreta. Acta Obstet Gynecol Scand 2013;92(4):386-91. 